This is an electronic reprint of the original article. This reprint may differ from the original in pagination and typographic detail.

Author(s): Wahlström, Jarl

Title: $\quad$ The researcher in the field : some notes on qualitative research in mental health

Year: $\quad 2017$

Version:

Please cite the original version:

Wahlström, J. (2017). The researcher in the field : some notes on qualitative research in mental health. European Journal of Psychotherapy \& Counselling, 19(1), 97-109. https://doi.org/10.1080/13642537.2017.1289972

All material supplied via JYX is protected by copyright and other intellectual property rights, and duplication or sale of all or part of any of the repository collections is not permitted, except that material may be duplicated by you for your research use or educational purposes in electronic or print form. You must obtain permission for any other use. Electronic or print copies may not be offered, whether for sale or otherwise to anyone who is not an authorised user. 
Jarl Wahlström ${ }^{1}$

\title{
The Researcher in the Field - Some Notes on Qualitative Research in Mental Health
}

\section{Author's Accepted Manuscript}

To cite this article: Jarl Wahlström (2017) The researcher in the field - some notes on qualitative research in mental health, European Journal of Psychotherapy \& Counselling, 19:1, 97-109, DOI: 10.1080/13642537.2017.1289972

\begin{abstract}
In this published response to five studies in the present special issue, all representing qualitative research in the field of mental health, this research is approached as cultural and social practice. The five studies are looked upon as informative examples of research activity in mental health, and it is asked how that particular field is conceptualised as a form of human activity, how the authors position themselves in relation to the field, why they ask the questions they seek to answer, and how epistemic queries concerning knowing and not-knowing manifest themselves and are addressed in the studies. The paper seeks to contribute to the debate on the uses of qualitative methodology in mental health research by explicating some of the differences and some of the similarities between pieces of research at hand.
\end{abstract}

Keywords: mental health, qualitative research, lifeworld, action field, preunderstanding, emancipatory interest

\footnotetext{
${ }^{1}$ Department of Psychology University of Jyväskylä Jyväskylä, Finland
} 


\section{The Researcher in the Field - Some Notes on Qualitative Research in Mental Health}

In their joint editorial to the previous special issue of this journal devoted to developments in qualitative research in mental health, Loewenthal and Avdi (2016) somewhat provocatively asked whether research in psychotherapy and counselling is a waste of time. Having been asked to write a published response to the five studies in the present special issue I would like to subscribe to Loewenthal's and Avdi's notion that research should be looked upon as cultural and social practice. I will not, however, attempt an answer to their question. Rather, I will look upon the five studies as informative examples of research in mental health, with the intention of taking a closer look at what might be going on in that practice. I will, in particular, ask how, in those studies, some concrete instances of human encounters are constructed as occasions of mental health work, worthy of shedding some light on questions pertinent to that field; how the authors appear to position themselves in relation to the field, why they ask the questions they seek to answer and how epistemic queries concerning knowing and not-knowing are addressed - or fail to be addressed.

\section{Encounters in Mental Health}

Let me start this "investigation" by presenting the "basic data". The five papers included in this special issue offer us, as readers, accounts of the following encounters between people:

- In the UK a female counselling psychologist was contacted by a man, presently employed in an enterprise, but with an earlier work history of five years of military service in elite forces (Challenor, 2017). The reasons he gave for making contact was his feelings of anxiety and panic, his thoughts about committing suicide and his fear of breaking down psychologically. They agree to start meeting regularly at the psychologist's independent practice, thus establishing a professional psychotherapeutic relationship. After 12 months of treatment, 
the relationship is unilaterally ended by the male client, much to the surprise and even shock of the practitioner.

- In Italy a family therapy team, working in a private institute, was approached by a married, academically educated and professionally active couple (Salamino \& Gusmini, 2017). The couple requested consultation regarding the trouble they experienced with their 15 years old adoptive son. The therapeutic team meets the parents twice and all the three family members seven times during a period of ten months in therapy sessions of two hours' duration, and later at two follow-up meetings 18 and 34 months respectively after the end of the treatment.

- In Ireland a male university lecturer and psychoanalytic practitioner went to units - acute inpatient settings, day hospitals and community services - of adult psychiatric services to observe how staff members act and interact with patients in so called critical incidents, and to talk with them, both informally and in more formal interviews, about those incidents and their experience of them (Moore, 2017). He defines critical incidences as sudden and unexpected events outside the range of normal experience which may lead to a sense of threat and loss of control.

- In the UK two female clinical psychologists invited staff members from crisis resolution home treatment teams to talk to each other in so called focus groups (Iliopoulou \& Sacks, 2017). The task of the staff is to respond rapidly and appropriately to people experiencing a mental health crisis. In their work staff meet with high risk situations almost daily and the intent of the invitation to the focus groups was to offer them an opportunity to talk about the risks met and managed by the teams. The staff members meet in groups of four or five and have their discussions facilitated by one of the researchers. 
- In the UK a female systemic psychotherapist working in a small island community has been involved with establishing and facilitating support groups for women who have been sexually abused (Salter, 2017). She is in many ways participating in the life of the community and of the women attending the support group and has talks with them in different settings. She starts to give her activities the title "conversational inquiry", and to ponder on the interrelations of her positions as practicing therapist, group facilitator, member of the community and doctoral researcher.

There are some observations we as readers can make on these encounters. Although in many respects different and even unique, they have some shared features. Since they have been reported in a scientific conference we can be confident that they have actually taken place. The persons involved and the events described are not fictions. The social context of all the encounters is professional, and in this sense public. And more precisely, the professional context of each encounter relates somehow to the societal institutional field of "mental health". As such they involve two categories of participants - practitioners and clients. The interests and reasons for participating in the encounters are different for the representatives of those two categories. They have dissimilar roles and positions with respect to the institutional task of the encounters.

Yet another common feature of these encounters is that they have been taken as source for data for qualitative inquiry into some aspect of professional activities in "mental health". From the myriads of encounters going on in that field, these have been selected to shed some light on what is going on in such encounters, to answer some question concerning mental health work practices. It also appears that beyond asking questions is also an intent, at least implicitly, to draw conclusions about some of those practices, to validate and encourage or to criticize and discourage their uses. 


\section{The Lifeworld and the Field}

The description above of the human encounters which formed the data basis of the five studies reported in this special issue was intended to be as factual as I could make it. Not factual in the sense of being as comprehensive as possible but factual in the sense of not being "interpretative". These were the participants and these were the contexts in which they met. Of course even such a presentation involves "interpretations". Using words such as "therapy", "anxiety", "adoptive family", "critical incidents", "mental health crisis" and "sexual abuse" the encounters are already cast into a social world, created by human communication and meaning-making, and identified as particular instances of that world.

What was given above is then not merely an introduction to the life conditions of the people involved in the encounters but one of the lifeworld of the participants. While, according to Kraus (2015), the concept of life conditions refers to the material and immaterial circumstances of people's life, by the concept lifeworld reference is given to peoples' subjective constructions of reality, which they form under the condition of their life circumstances. Action, knowing and consciousness are embedded in and operating in a world of meanings and pre-judgements that are socially, culturally and historically constituted.

Encounters in psychotherapy and other forms of mental health work become, so to speak, sections of the lifeworld of the participants. I will call such sections action fields. Constituting, within the lifeworld of the participants, an encounter as a particular instance of the action field of mental health interventions is an achievement involving both subjective (i.e. private) and social (i.e. collective) meaning-making. The uses of words such as "treatment", "panic", "trauma", "out of control" etc. establish a communicative medium for the gradual co-ordination of meanings (Pearce, 2007) that are given to the experiences and life-events of (mostly) the client-participants. 
The participants subscribe to the use of discourses which are appropriate to the forms and goals of the encounter in its distinctiveness as an instance of mental health work. (In animal assisted therapy the dog or the dolphin may be experienced by the client as "therapeutic", and even denoted as a "therapist", but it is unlikely that these ascriptions in any way would correspond to the animal's experience - it may enjoy the situation, though!).

Now, how do the participants in mental health work, as players in that particular subfield of their lifeworld, identify and (co-)create their common activities as instances of the appropriate social forms of that field? What kinds of actions are more successful in achieving outcomes that are perceived to be desirable, and what kinds of actions are less successful? Are there forms of activities which could be seen as "effective" from some point of view but considered as undesirable or even unethical from a wider perspective? To what extent do the "players" need to have a shared understanding of their joint meaning-making? These are the kind of questions that present themselves as particularly appropriate to be addressed by the methodological means of qualitative inquiry.

Obviously none of the five studies attempt to answer all of these questions. When designing his/her study each researcher has made choices concerning how the relevant field of study is defined and delimited, what are the pertinent questions to be asked and what methods of inquiry are appropriate for eliciting trustworthy reconstructions of the study participants' lifeworld within the particular action field under investigation. Some of these choices have been conscious and deliberate, and accounted for in the study report. Others may have been less reflected upon by the researcher.

\section{The Researcher and the Field}


The social action field of mental health work and interventions is established, maintained and transformed through social practices by numerous "players" in a large variety of contexts, on many "levels", taking different roles and positions. Things go on, events unfold, deeds are done, words are spoken - "the whole hurly-burly of human actions" (Wittgenstein, 1981, No.567). How can this in its overwhelming multitude be appropriated by research?

It cannot. For the purpose of scholarly inquiry, the researcher needs to delineate from the multitude of activities a set of practices, chosen to be the object of interest of the investigation. Doing this, the researcher takes an outsider perspective on the field. Some activities - things done or things said - are considered to be more relevant than others. How and why? Mostly this is done by the researcher or the research team in their capacity as "players" on another field, i.e. the social field of mental health research.

Still, since many of mental health researchers are also practitioners in the field, an interesting intersectionality is established. And what is more - many do research on their own professional work. Of the five studies this was the case in three pieces of research (Challenor, Salamino \& Gusmini, Salter). Apparently also Iliopoulou and Sacks are closely affiliated to the organisation they are investigating. Only Moore, a trained psychoanalytic practitioner, seems to have an outsider position with respect to the practices he is reviewing.

This intersectionality means that the choices of the researcher are profoundly affected by how his/her lifeworld is constituted. The researcher's understanding, allegiances, and the discourses he/she subscribes to influence the total research process. The complexity of research into mental health interventions is further accentuated by the fact that these are intersectional in themselves. On the one hand they have the societal status of professional and hence public activities, whilst on 
the other hand mental health interventions necessarily dig deep into the private lifeworld of clients, and cannot fail to touch also those of the practitioners.

Obviously, for the researcher, having the double position of a "player" in the field of practice who takes the step over into the field of research has both advantages and disadvantages. An insider has access to tacit knowledge and understandings of the field which open possibilities of comprehending what is going on that perhaps never are available for an outsider researcher. Such pre-understanding of the many subtleties of, let us say, interaction in psychotherapy may be a prerequisite for any analysis of therapeutic processes. Then again, an un-reflected stance towards one's perceptions of the practices under scrutiny, may make the researcher blind to significant features of the interactions which easily stand out for researchers whose observations are guided by some other tradition of conceptualising human encounters. There is a complex dialectic between preunderstanding and not-knowing (Bleicher, 1980) in qualitative research on mental health.

\section{Roles and Positions in the Five Studies}

Roles define the expectancies participants in institutional encounters have of the actions performed by themselves and others (Suoninen \& Wahlström, 2009). The differences between the roles of a practitioner and a client in mental health are relatively clear, as are the differences between a researcher and a study participant in qualitative research. However, when taking up a role and adhering to it, a person can still adopt a large variety of positions in regard to whatever is encountered while performing the role.

In two of the five studies (Challenor; Salamino \& Gusmini) the writers adopted the double role of being both therapist-participants and researchers. The positions they took with respect to the therapy cases under investigations were, however, quite different. The motivation for Challenor to 
look in close detail at the present case appears to have been her experience of the treatment as having an unexpected and unsatisfactory outcome. Using concepts from inter-subjective, relational psychoanalysis she seeks to throw light on the client's choice to leave treatment without the consent of herself as therapist, and much to her disappointment. This study, then, carries two contributions. First, to give the author (and readers) a new and deepened understanding of the events that took place, and second to elaborate on the applicability of some theoretical concepts (here especially the relational understanding of dissociation).

The motivation for the Salamino and Gusmini case study is different. The intent is to present a case with satisfactory outcome and use it as a demonstration of a particular therapeutic approach. The authors use the case study as one instance of confirmation of the plausibility of their approach and even its advantage over another one. The specific argument here is that in adoptive families too much concern about the adopted child's (supposed) inadequate early attachment relationships will lead to attributions and explanations of the child's problematic behaviours that are counterproductive for finding solutions to the present-day difficulties. Focusing on current relationships and patterns of mutual connection in the present is given as a more viable alternative.

The studies by Moore and by lliopoulou and Sacks have in common that both are concerned with complicated encounters between staff and patients in mental health institutions. In both studies the authors adopt the role of researchers approaching "the field" from outside. But again the positions taken by the researchers in the two studies are very different. Moore goes into the organisation as a non-participant observer and occasional interviewer, and furnished with a very specific conceptual instrument: a lens informed by specific, mainly Freudian and Lacanian, aspects 
of psychoanalysis. This lens enables him to see events (critical incidents) and detect meanings in them that are in some respect hidden from the staff members themselves as "players in the field". Iliopoulou and Sacks on the contrary invite the staff to focus groups and ask them to discuss how they manage risks in their work with clients in the home environments of these clients. Apart from defining the theme of the focus groups, the researchers do not bring into the formation of the data any conceptual framings of their own. They state as their intent to help the team to understand how they presently manage risks and to generate ideas to aid them manage risk better in the future. Using Interpretative Phenomenological Analysis when reading the data, the researchers mainly "give back" the discussions to the participants, but now more conveniently ordered and opened up as categories of themes.

The role and position of Salter in her study is quite complex. She defines her investigation as "inside research", and it appears that this "insider" position takes many forms. First, the women with whom she has conducted what she names as "conversational inquiries" are women she has either co-facilitated groups with or who have attended those groups. In this sense she is researching her own practice. But then actually not so because her interest is in the activities of these women as members in the community of which she also is a member, and as members with a particular point of view (which she also shares): that of women who have experiences of oppression and abuse, and who have, in spite of that, found their ways of "going on" in their lives. Third, the paper itself is, at least in my reading, not actually a report on the findings of those "conversational inquiries" but has perhaps more the character of an essay or even a testimonial on the role and position of the researcher as an insider.

\section{Epistemic asymmetry}


The position of a qualitative researcher with respect to the actors of the particular field of study is often compared to that of an anthropologist entering an exotic society. In such an ethnographic approach the researcher is expected to acknowledge his/her unfamiliarity with the social practices of the action field and the actors' understandings of them. This notion of the researcher taking up a not-knowing position with respect to the field of study is problematic in research on psychotherapy and other mental health interventions at least for two reasons. First, as noted above, most researchers are actual practitioners in the field and are necessarily informed in their investigations by quite elaborate preunderstandings, not easily bracketed (Fischer, 2009) from the analysis. Second, the phenomena related to mental health exhibit in themselves an intriguing condition of epistemic asymmetry (Weiste, E., Voutilainen, L. \& Peräkylä, A. 2015).

Mental health problems are usually manifested in a person's sense of psychological distress and difficulty to master some aspects of his/her life. Such a sense of lost agency (Wahlström \& Seilonen, 2016) is in psychological theories attributed to some kind (and there are a plenty on offer) of deficiency in the function of the person's "mind". In psychological interventions clients are invited to observe and reflect on the workings of their "minds", and in that process it is, at least implicitly, accepted that the person in the role of therapist or some other kind of mental health practitioner has somehow some kind of access to the client's "mind". Such an epistemic asymmetry, where the professional knows something about the client's way of experiencing and relating to that experiencing that is not known to the client him/herself, is subtly subscribed to by the participants in therapeutic relations.

For practitioner-researchers in the mental health field there arises then tensions between the somewhat idealistic notion of the researcher as a not-knowing but hermeneutically able "visitor" to the lifeworld of the actors in the field and as an actor in his/her own right with inside 
knowledge of the social practices involved, and even such knowledge of some other actors' (clients or other study participants) grounds for their actions that is not fully accessible to themselves. How are these tensions manifested in the present five studies?

For Challenor the challenge in the clinical situation was to help her client to gain access to and reframe violating and abusive experiences from his childhood and to relate them in a meaningful way to his present conduct in adult life - a typical instance of epistemic asymmetry in psychotherapy. When it turned out, in the therapeutic process, that this course of action, meant to be helpful, actually made the therapy turn into a threat to the well-being of the client, Challenor redirected her curiosity. Now, taking the position of a researcher, she started to inquire into her own conception of the psychological phenomenon supposed to be at work, i.e. dissociation. By reading the literature on dissociation, informed by relational psychoanalysis, and applying those conceptualisations, she constructed an account of the therapeutic process that made new sense of what happened. The "epistemic gain" gathered from this process is what we as readers are given.

Salamino and Gusmini, in their study (and in their practice), criticise the use of attachment theory as a ground for preunderstanding predicaments adoptive families may find themselves in, especially with respect to the conduct of the adoptive child. This could be seen as a confrontation of the notion of epistemic asymmetry in therapeutic relations, in favour of a more egalitarian setting in which therapists and clients together set out for a joint exploration of the field of relational patterns in the families involved (the biological family, the adoptive family, the extended families of the adoptive parents). What we actually find, however, when reading the study, is that the therapists use, with considerable force, very definite tools for interpretations when challenging the family members' understandings and attributions - the most prominent being "a 
non-individual, non-innate triadic way of understanding". In my view, the use of these tools, beneficial as it seems, introduces a structure of epistemic asymmetry in the process.

Moore as researcher, on his part, positions himself as possessing tools for interpretation not accessible to the actors in the field of his study. Here we meet an unapologetic recognition of epistemic asymmetry grounded on the psychoanalytic notion of unconscious motivation. The study in itself does not include any intervention but suggests that supervision, aimed at reassuring staff to use their natural skills of understanding, and applying an interpretative psychoanalytic stance, would have an effect of making the interaction between staff and patients in mental institutions more open, free and human. What one finds oneself asking is: how can interpretations, taken from a position of knowing, be validated? In what sense is e.g. the talk about a vomit stain on a carpet somehow "really" connected to the unconscious wish of the staff to get rid of a recalcitrant patient? Some proponents of psychoanalytic hermeneutics (e.g. Laplanche, 1992) would hold that the only criterion of validity is whether the communication between analyst and analysand is restored - a criterion Moore could not use in his study. Restoring communication could be equated to a momentary alleviation of the epistemic asymmetry which then reemerges when further analytic work is required.

Iliopoulou and Sacks appear as the two researchers who most clearly adopt a position of notknowing when approaching the lifeworld of the actors in their field of study. They put an open question concerning risks met and managed by staff in the home service. It is interesting, then, that even when there were many kinds of experiences that could have been discussed in response to the question groups focused on two areas, namely aggression and violence and challenging suicidal behaviour. There seems to have been in the groups some kind of a shared understanding of what is meant by 'risk'. This could be because these situations are the most common ones 
actually met by staff in their work. But then again, this shared (pre)understanding could cover other possible issues worth of consideration.

Salter is the second author in this selection, beside Moore, who takes an unapologetic stance with respect to her position of knowing as a researcher. Her standpoint is, though, quite different from that of Moore's. Her knowing is the shared knowing of individuals who occupy similar positions in the community, in this case the position of sexually abused women who have experienced the double abuse of not having their experience validated at the level of relationship, community or society. In relation to this group of actors in the field the researcher places herself within perfect epistemic symmetry. The epistemic asymmetry is constructed with regards to the rest of the community, those who either actively disregard the experience of the abused and oppressed members or who do it passively by not paying attention. From the point of view of political action this is, obviously, a justified stance. From the point of view of research, however, one could argue that the total pattern of meaning-making on which the unjust social practices are being maintained is not revealed in its whole complexity.

\section{Some Conclusions}

The most obvious "finding" of my small investigation into practices of doing qualitative research in mental health, exemplified by the five studies in this special issue, is that this is a set of procedures with great diversity. This is of course nothing novel or surprising but perhaps my minor exercise can contribute to explicate some of the differences and some of the similarities between pieces of research.

In all of the studies the authors were closely connected to the action field of mental health, actually having as their main occupation some kind of practice in that area. This seems to be the rule, with few exceptions, in this range of research, especially in studies employing qualitative 
methodology. From this follows that most of those undertaking such investigations, actually are "lay-researchers". This was the case in most of the present five studies. The advantage of having practitioners doing research is that they possess valuable insight into the social practices of the field. But this, of course, is a two-edged sword, since it may prevent the researcher perceiving what in those practices might present itself as strange, and even undesirable, when looked upon and experienced from another perspective.

It goes without saying, that the lay position of the researcher also has some bearing on the quality of research as an academic performance. It is not my prerogative to comment on the five studies from this point of view. What I would like to take note of is that the multitude of human activities within the action field of "mental health" actually are representative of many aspects (i.e. also non-clinical) of the human condition, and can as such be of interest to academics in human sciences at large, even when their main orientation is towards basic research. One would like to see more of fruitful collaboration between practitioner-researches and "professional" researchers. When it comes to the motivation and intent to do research one could observe clear differences between the five studies. Some of the studies were oriented towards looking at particular interventional practices, either with the aim of critically examining a certain practice or to propagate the use of some practice in the field. Other authors were concerned with institutional routines or procedures in mental health organisations, or social attitudes towards those affected with mental health problems. What all of the studies had in common, was the intention not only to describe a certain state of affairs, but to have an impact on how practices are performed. Such an emancipatory interest was more clearly articulated in some studies, but was nevertheless observable in all of them. Laudable as such goals are, I did find myself wishing for even more detailed descriptions of what actually "was going on" in the encounters. 
From a philosophical point of view, what seemed to create the greatest difference between the studies was the authors' stance towards the epistemic polarity between knowing and notknowing. In hermeneutics, the division is thought to be bridged when knowing is conceptualised as pre-knowledge, a necessary precondition for the not-known to be known. I have drawn upon the notion of "epistemic asymmetry" to deliberate on how this is being actualised in therapeutic encounters. It seems that a difference in knowing between therapist and client is essential for therapeutic progress, even as such differences also may lead to unintended and even abusive practices. The dilemma of pre-knowledge, both in the relationship between practitioners and clients and between researchers and study participants, was present in all the studies but did not, in my judgement, get the mindful attention it would have deserved.

Returning then to my point of departure, I find that it is definitively appropriate to look at the five studies as social practice, i.e. as acts meant to be meaningful and to have an impact on the lived world and the lifeworld of people "playing" as actors in the social field called "mental health". I would like to invite the reader to make a thought experiment: how would a study on e.g. Challenor's data look like if it was conducted by Salter; or a study on Iliopoulou and Sacks data as analysed by Moore? It is obvious that the same concrete human encounters would afford different researchers to do different things with them. So what in the end might be the benefit of doing qualitative research in mental health? Perhaps, as Salter might put it, - to find new ways to "go on".

\section{References}

Bleicher, J. (1980). Contemporary hermeneutics; Hermeneutics as method, philosophy and critique. London: Routledge \& Kegan Paul.

Challenor, J. (2017). 'Not dead...abandoned' - A clinical case study of childhood and combatrelated trauma. European Journal of Psychotherapy \& Counselling, 19, forthcoming. 
Fischer, C.T. (2009). Bracketing in qualitative research: Conceptual and practical matters. Psychotherapy Research, 19, 583-590. DOI: 10.1080/10503300902798375

Iliopoulou, M. \& Sacks, M. (2017). The impact of professional role on working with risk in a home treatment team. European Journal of Psychotherapy \& Counselling, 19, forthcoming.

Laplanche, J. (1992). Interpretation between determinism and hermeneutics; A restatement of the problem. International Journal of Psychoanalysis, 73, 429-445.

Kraus, B. (2015). The life we live and the life we experience: Introducing the epistemological difference between "Lifeworld" (Lebenswelt) and "Life Conditions" (Lebenslage). Social Work and Society. International Online Journal, 13. Retrieved from:

http://www.socwork.net/sws/article/view/438

Loewenthal, D. \& Avdi, E. (2016). Is research in psychotherapy and counselling a waste of time? European Journal of Psychotherapy \& Counselling, 18, 311-315, DOI: 10.1080/13642537.2016.1261651

Moore, G. (2017), Critical incidents in mental health units may be better understood and managed with a Freudian/Lacanian psychoanalytic framework. European Journal of Psychotherapy \& Counselling, 19, forthcoming.

Pearce, W.B. (2007). Making social worlds: A communication perspective. Oxford: Blackwell.

Salamino, F. \& Gusmini, E. (2017). A shift in narratives: from "attachment" to "belonging" in therapeutic work with adoptive families. A single case study. European Journal of Psychotherapy \& Counselling, 19, forthcoming.

Salter, L. (2017). From victimhood to sisterhood part II - Exploring the possibilities of transformation and solidarity in qualitative research. European Journal of Psychotherapy \& Counselling, 19, forthcoming.

Suoninen, E. \& Wahlström, J. (2009). Interactional positions and the production of identities: Negotiating fatherhood in family therapy talk. Communication \& Medicine, 6, 199-209.

Wahlström, J. \& Seilonen, M-L. (2016). Displaying agency problems at the outset of psychotherapy. European Journal of Psychotherapy \& Counselling, 18, 333-348. DOI: 10.1080/13642537.2016.1260616

Weiste, E., Voutilainen, L. \& Peräkylä, A. (2015). Epistemic asymmetries in psychotherapy interaction: Therapists' practices for displaying access to clients' inner experiences. Sociology of Health and IIIness, 38, 645-661. DOI: 10.1111/1467-9566.12384

Wittgenstein, L. (1981). Zettel, (2nd. Ed.), G.E.M. Anscombe and G.H.V. Wright (Eds.). Oxford: Blackwell. 